\title{
Modified Warden operation using aortic homograft
}

\author{
T. K. Susheel Kumar, MD, ${ }^{\mathrm{a}}$ David Chen, MD, ${ }^{\mathrm{a}}$ Dan Halpern, MD, ${ }^{\mathrm{b}}$ Puneet Bhatla, MD, ${ }^{\mathrm{b}}$ \\ Sunil Saharan, MD, ${ }^{\mathrm{b}}$ Michael Argilla, MD, ${ }^{\mathrm{b}}$ and Ralph Mosca, MD, ${ }^{\mathrm{a}}$ New York, NY
}

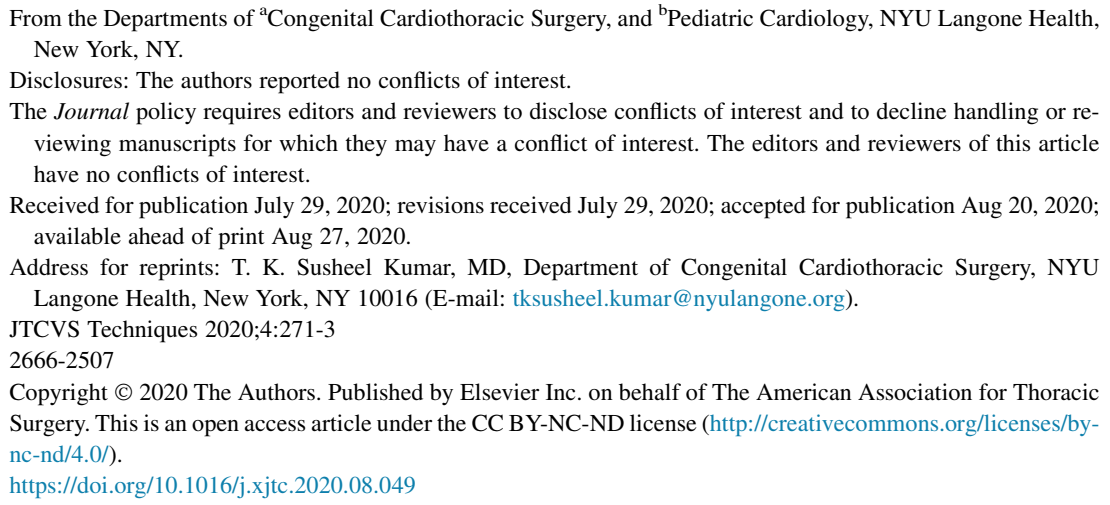

Video clip is available online.

A 57-year-old woman presented to the cardiology clinic with exertional dyspnea. Transthoracic echocardiogram demonstrated partial anomalous pulmonary venous connection (PAPVC) of the right upper and middle veins to the superior vena cava (SVC), an intact atrial septum, enlarged right ventricle, moderate tricuspid regurgitation, and pulmonary hypertension. Cardiac magnetic resonance imaging confirmed the diagnosis with the right upper and middle pulmonary veins connecting to the SVC high above the cavoatrial junction and a Qp to Qs ratio of 2 . Cardiac catheterization also confirmed significant pulmonary hypertension with indexed pulmonary vascular resistance of 9.4 Woods units $/ \mathrm{m}^{2}$ and some reversibility with oxygen. She was treated with pulmonary vasodilator therapy for 2 months before operation. This case report does not contain any patient identifiers and is hence exempt from institutional review board review as per institutional guidelines.

Following a median sternotomy, a large patch of autologous pericardium was harvested and treated with glutaraldehyde. The right upper pulmonary veins connected to the SVC about 3 to $4 \mathrm{~cm}$ above the cavoatrial junction, which in the context of a short broad right atrial appendage made a conventional Warden procedure technically impossible. The patient was placed on cardiopulmonary bypass via cannulation of aorta, inferior vena cava, and innominate (Figures 1 and 2).

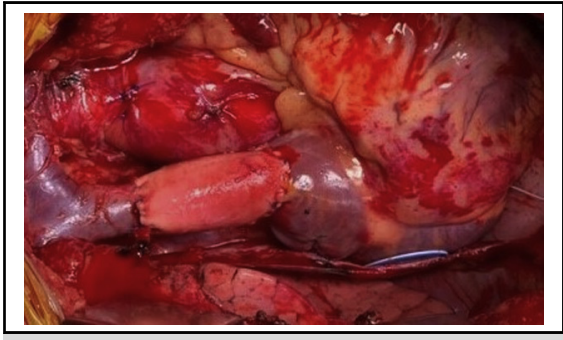

Aortic homograft conduit interposed between proximal superior vena cava and right atrium.

\begin{abstract}
CENTRAL MESSAGE
High connection of anomalous pulmonary veins to the superior vena cava may warrant modification of classic Warden operation in the form of an interpositional graft. Aortic homograft is a good choice.
\end{abstract}

See Commentaries on pages 274 and 275 .

vein and cooled to $30^{\circ} \mathrm{C}$. The azygous vein was ligated and divided. Following myocardial arrest, a vertical atriotomy was performed. A large secundum atrial septal defect was created by excision of the fossa ovalis. The SVC was divided immediately above the PAPVC. The distal opening of the SVC was closed primarily. An intracardiac baffle of treated pericardium was created between the opening of the SVC and the atrial septal defect. Given the long distance between the proximal SVC and the right atrial appendage, an interpositional tube graft was deemed necessary. An 18-mm $\times 5-\mathrm{cm}$ aortic homograft (CryoLife, Inc, Marietta, $\mathrm{Ga})$ was introduced into the field and the proximal valved portion was excised. The remaining nonvalved portion was placed as an interposition conduit between the proximal SVC and an opening in the right atrial appendage

The right atriotomy was closed, the aortic crossclamp was removed, and the patient was weaned off cardiopulmonary bypass in normal sinus rhythm (Video 1). Inhaled nitric oxide was used intra- and postoperatively. Postoperative echocardiogram demonstrated good function and unobstructed flow in the intracardiac baffle and homograft. Postoperatively, she was treated with aspirin for 3 months and pulmonary 


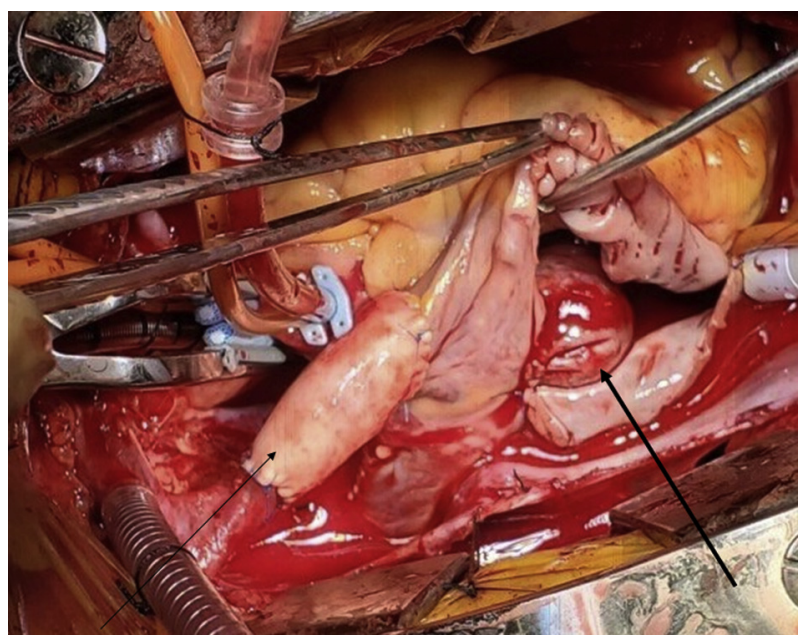

FIGURE 1. Aortic homograft interposition conduit (thin black arrow) between superior vena cava and right atrial appendage. Pericardial baffle (thick black arrow) seen through open right atrial incision.

vasodilator therapy was continued. Follow-up echocardiogram 5 months following the operation demonstrated laminar flow in the conduit with no gradient and significant reduction in estimated pulmonary artery pressure.

\section{DISCUSSION}

PAPVC is failure of 1 or 3 of the major pulmonary veins to connect to the left atrium during fetal development. The most common form is anomalous connection of the right upper and/or middle veins to the SVC. In about $20 \%$ of this form of PAPVC, the connection of the upper pulmonary vein to the SVC can be high, making conventional Warden operation difficult. ${ }^{1}$ In such a situation, the 1-patch technique is not a feasible option and the 2-patch technique is fraught with risk of sinus-node dysfunction. ${ }^{2}$ The caval division technique described by Warden in 1984 works well for most forms of PAPVC, with a low incidence of sinus-node dysfunction and obstruction of the systemic or

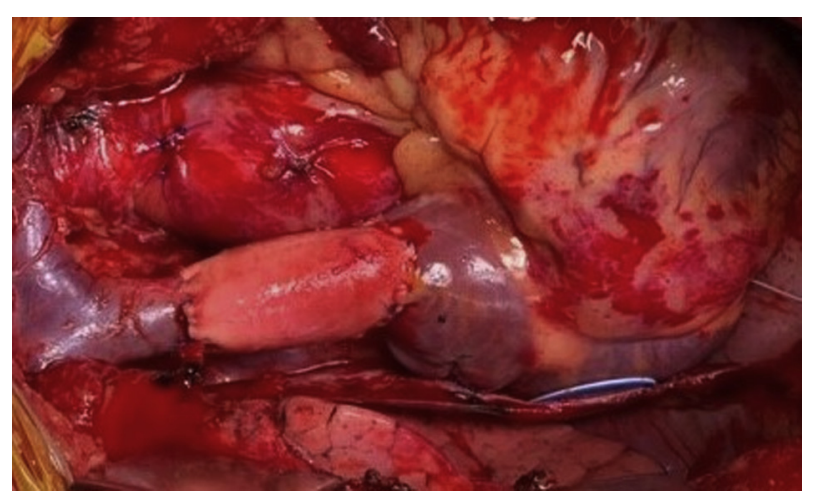

FIGURE 2. Aortic homograft conduit interposed between proximal superior vena cava and right atrium.

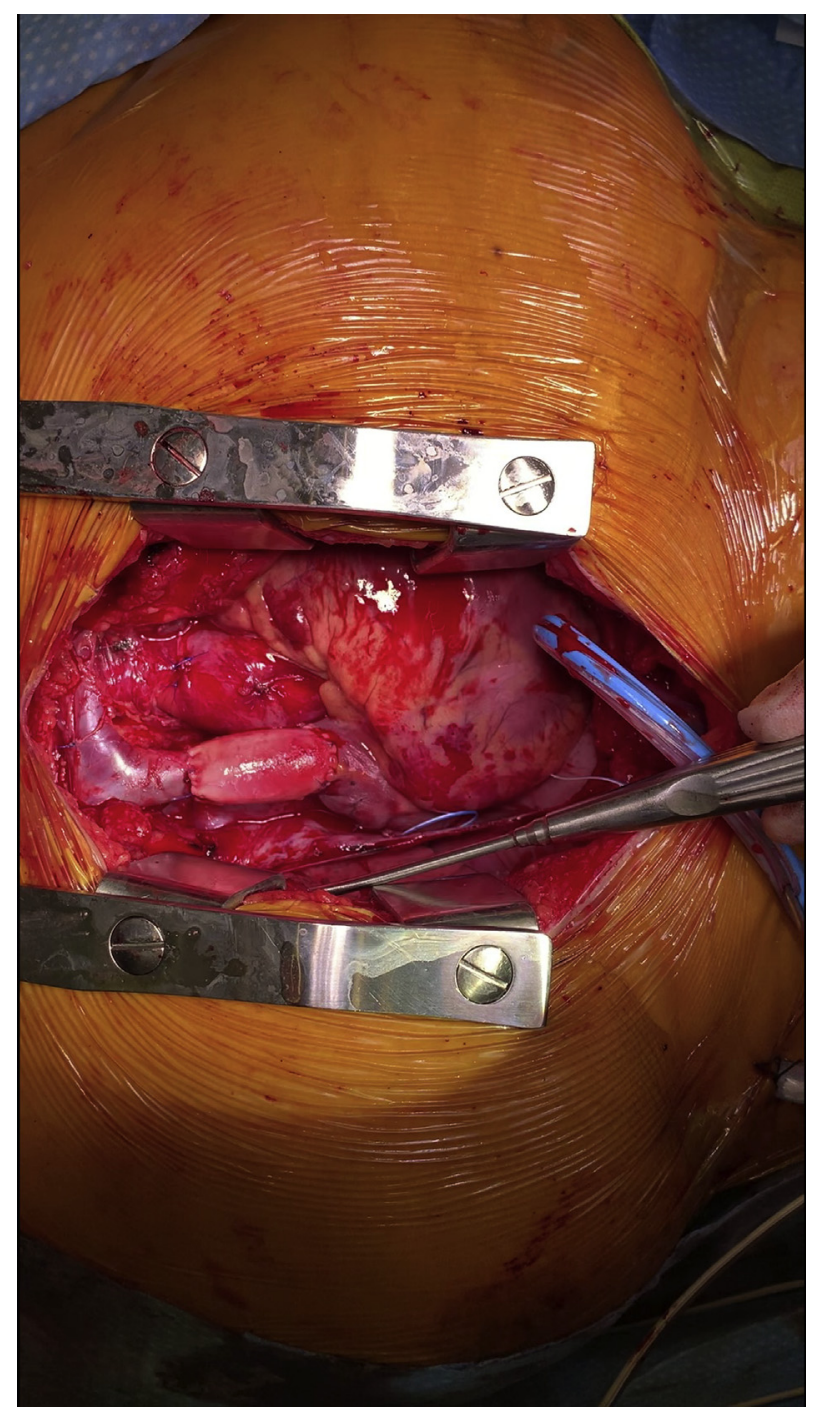

VIDEO 1. Video demonstrating final position of aortic homograft interpositional conduit between the superior vena cava and the right atrial appendage. Video available at: https://www.jtcvs.org/article/S2666-2507 (20)30428-4/fulltext.

pulmonary venous flow. ${ }^{1,3,4}$ However, high insertion of the pulmonary veins into the SVC with resulting short residual segment of SVC, particularly in association with short right atrial appendage, renders the classic Warden procedure extremely challenging. The risk of SVC stenosis from excessive tension on the suture line is also well described in such situations.

Modifications of the classic Warden procedure have been described to overcome such shortcomings. ${ }^{1,5}$ Tao and colleagues ${ }^{5}$ described creation of right atrial flap to reach the cephalad end of the SVC and used a pericardial patch anteriorly to construct the cavoatrial channel. Sinus-node dysfunction and SVC stenosis are risks with this modification. Said and colleagues ${ }^{1}$ described the use of the short 
segment of a ringed Gore-Tex (W. L. Gore \& Associates, Inc, Flagstaff, Ariz) graft between the SVC and right atrial appendage for patients with high PAPVC with good outcomes. The patients were treated with coumadin (BristolMyers Squibb, Princeton, NJ) for 3 months. Our technique of using a nonvalved segment of aortic homograft is technically easy and serves as an alternative to Gore-Tex graft. The aortic homograft is hemostatic, rigid, and has a natural curve that can be used to advantage. The endothelial lining also likely makes it less thrombogenic. However, the longterm consequences of homograft degeneration and calcification, although a short nonvalved segment, in this position are unknown.

\section{References}

1. Said SM, Burkhart HM, Dearani JA, Eidem B, Stensrud P, Phillips SD, et al. Outcome of caval division techniques for partial anomalous pulmonary venous connections to the superior vena cava. Ann Thorac Surg. 2011;92:980-4; discussion 985 .

2. Stewart RD, Bailliard F, Kelle AM, Backer CL, Young L, Mavroudis C. Evolving surgical strategy for sinus venosus atrial septal defect: effect on sinus node function and late venous obstruction. Ann Thorac Surg. 2007;84:1651-5; discussion 1655.

3. Warden HE, Gustafson RA, Tarnay TJ, Neal WA. An alternative method for repair of partial anomalous pulmonary venous connection to the superior vena cava. Ann Thorac Surg. 1984;38:601-5.

4. Shahriari A, Rodefeld MD, Turrentine MW, Brown JW. Caval division technique for sinus venosus atrial septal defect with partial anomalous pulmonary venous connection. Ann Thorac Surg. 2006;81:224-9; discussion 229-30.

5. Tao K, Pan W, Lin K, Shi Y, Zhu P, Guo Y, et al. Modified cavoatrial anastomosis in Warden procedure. Ann Thorac Surg. 2010;89:2047-8. 